\title{
Literatura infantil brasileira: da colonização à busca da identidade
}

José Nicolau Gregorin FilHo

Universidade de São Paulo

RESUMO: O PRESENTE TRABALHO BUSCA REVER O CONCEITO DE IDENTIDADE NACIONAL BRASILEIRA NO ÂMBITO DA LITERATURA INFANTIL, RELATIVIZANDO O ASPECTO HISTÓRICO E CRONOLÓGICO QUE O VEM NORTEANDO E ENFATIZANDO A VINCULAÇÃO DESSE GÊNERO ÀS PRÁTICAS SOCIAIS QUE FORAM SE IMPONDO À COMUNIDADE E À EDUCAÇÃO FORMAL NO BRASIL APÓS O SÉCULO XIX.

ABSTRACT: THIS ESSAY AIMS TO RECONSIDER THE CONCEPT OF BRAZILIAN NATIONAL IDENTITY IN THE LITERATURE FOR CHILDREN, ARGUING THAT THE CHRONOLOGICAL AND HISTORICAL ASPECTS INVOLVED IN ITS DEFINITION ARE LESS IMPORTANT THAN THE CONSTITUTION OF THIS LITERARY GENRE IN RELATION TO THE SOCIAL PRACTICES AND BRAZILIAN FORMAL EDUCATIONAL PATTERNS ALONG THE XIX AND THE XX CENTURIES.

PALAVRAS-CHAVE: LITERATURA INFANTIL - IDENTIDADE NACIONAL - LITERATURA E EDUCAÇÃO - LITERATURA E HISTÓRIA - LITERATURA E COLONIZAÇÃO KEY-WORDS: LITERATURE FOR CHILDREN - NATIONAL IDENTITY - LITERATURE AND EDUCATION - LITERATURE AND HISTORY - LITERATURE AND COLONIZATION 
maioria dos estudiosos de literatura infantil preconiza como ponto de partida para as suas explorações acerca da origem desse tipo de texto no Brasil a primeira metade do século XIX, já que foi nesse tempo que o país iniciou sua caminhada de emancipação da Metrópole e, em conseqüência disso, deu início a uma tentativa de progresso econômico e buscou conquistar a cultura que provavelmente o colocaria no rol das nações civilizadas do Ocidente.

Neste texto, utilizando como fundamentação teórica alguns elementos dos Estudos Comparados de Literatura de Língua Portuguesa, o objetivo é discutir o conjunto de produções literárias que se convenciona como de "literatura infantil" como uma expressão artística criada na e pela sociedade num processo histórico, que se inicia com a chegada dos colonizadores portugueses e caracteriza-se pela informalidade dos primeiros contatos com os nativos e, posteriormente, faz-se sentir por meio das diversas propostas educacionais importadas do estrangeiro desde o século XIX e que se fazem notar até meados da década de 1980.

Partindo do pressuposto de que os textos convivem em constante diálogo na sociedade e são construídos por meio de múltiplas linguagens, pretendese colocar em discussão as diferentes produções de sentido oriundas desse tipo de produção textual, ocasionadas pela instauração de narradores em diferentes lugares discursivos e ideológicos, já que os textos, numa leitura mais apurada e plural, fazem alusão a temas fundamentais da sociedade e são fruto da experiência individual-social-cultural, como a questão do gênero, da alteridade, das tradições culturais e religiosas, entre outras. Tomamos, para tanto, a seguinte citação de Miedviédiev:

A estrutura literária, como qualquer outra estrutura ideológica, refrata a sociedade socioeconômica que a gera, mas o faz ao seu modo. Ao mesmo tempo, porém, em seu "conteúdo", a literatura reflete e refrata as reflexões e refrações de outras esferas ideológicas (ética, epistemologia, doutrinas políticas, religião, etc.). O que quer dizer que, em seu "conteúdo", a literatura reflete a totalidade do horizonte ideológico de que ela própria é uma parte constituinte. O conteúdo da literatura reflete [...] outras formações ideológicas não artísticas (éticas, epistemológicas, etc.). Mas, ao refleti-las, a literatura engendra novas formas, novos signos do intercurso ideológico. E tais signos são obras de arte, que se tornam parte real da existência social que rodeia o homem. Refletindo algo externo a elas, as obras literárias constituem ao mesmo tempo fenômenos singulares [...]. Seu papel não 
pode ser reduzido ao [...] de auxiliar, de refletir outras ideologias. As obras literárias possuem um papel ideológico independente bem como seu modo particular de efetuar a refração da existência socioeconômica. (LOPES, 1993: 88)

Então, falar de literatura infantil é, de certo modo, vincular um determinado tipo de texto às práticas sociais que foram se impondo à comunidade e na educação oferecida para as novas gerações, principalmente no sentido da educação formal à qual nos referimos anteriormente e que tem seu lugar no Brasil após o século XIX.

Se o texto que se convencionou chamar de literatura infantil foi, durante muito tempo, apenas mais um dentre os parcos recursos disponíveis para o desenvolvimento da prática pedagógica, tomemos como ponto de partida alguns exemplos da obra Coração, de Edmondo De Amicis.

De Amicis foi um escritor italiano mundialmente conhecido. Nasceu em Oneglia, em 1846, e faleceu em 1908, deixando uma obra variada, em que se destacam narrativas de viagens, crítica literária, novelas, livros de temas sociais e políticos e um pequeno livro considerado obra-prima da literatura didática: Cuore. Escrita em 1886, a obra foi divulgada pelo mundo em milhares de edições, conquistando leitores de todas as idades e de todas as classes sociais - só na Itália, conta com mais de um milhão de exemplares.

As cenas desse livro e as suas figuras refletem e corporificam a variada e perturbadora alma humana nos seus anseios, sofrimentos, alegrias e paixões. Em Portugal, Ramalho Ortigão faz sua tradução em trechos e Miguel de Novais dá a versão portuguesa integral. No Brasil, Valentim Magalhães, em 1891, elabora sua tradução, entre fascinado e surpreso.

Dessa data em diante, Coração entra nas escolas brasileiras e na própria sociedade, passando a ser lido por todos, independentemente da faixa etária e da condição social, sendo um importante veículo para a concretização de ideais republicanos. A geração que se inicia no século XX aprende com ele lições de trabalho, de patriotismo, de virtude, de igualdade e de generosidade, sendo formada como eram formadas crianças e jovens italianos. Da obra, de cunho didático-moralizante, podemos selecionar algumas passagens:

Eu amo a Itália porque minha mãe é italiana, porque o sangue que me corre nas veias é italiano, porque é italiana a terra onde estão sepultados os mortos que minha 
mãe chora e que meu pai venera, porque a cidade onde nasci, a língua que falo, os livros que me educam, porque meu irmão, minha irmã, os meus companheiros, e o grande povo no meio do qual vivo, e a linda natureza que me cerca, e tudo o que vejo, que amo, que estudo, que admiro é italiano. (DE AMICIS, 1974: 74)

Fixa bem na mente este pensamento. Imagina que te estão destinados na vida dias tremendos; o mais tremendo de todos será o dia em que perderes tua mãe. Mil vezes, Henrique, quando já fores homem forte, experimentado em todas as lutas, tu a invocarás, oprimido por um desejo imenso de tornar a ouvir por instante a sua voz e de rever seus braços abertos para neles te atirares soluçando, como um pobre menino sem proteção e sem conforto. Como te lembrarás então de toda amargura que lhe causastes, e com que remorsos as pagarás todas, infeliz! (DE AMICIS, 1974: 28).

Por meio desses exemplos, já se pode perceber o endurecimento dos valores da época, ou seja, o texto leva o leitor a ter profundo respeito por todas as instituições que "governam" a vida do indivíduo: a família, a escola, a pátria. Há nesses trechos alguns exemplos dos valores de um país que lutava pela busca de sua identidade, além da constatação da influência portuguesa na educação brasileira, pois constitui um exemplo de obra largamente veiculada na Europa e trazida para o Brasil por meio de Portugal e, dessa maneira, com valores exteriores aos de nossa cultura e que se impunham por meio de uma educação copiadora de modelos europeus.

Em 1919, Tales de Andrade lança o livro Saudade, publicado pela Secretaria de Agricultura do Estado de São Paulo. Com ele, abre-se um caminho que vai ser um dos mais trilhados pela literatura infantil daí em diante: o rural, a busca pelos ideais da vida no campo.

O mundo acaba de sair de uma guerra, em que os valores da civilização urbana, progressista, haviam sido abalados na base, provocando nos homens a desesperança ou a descrença em sua legitimidade. A tendência geral na literatura apontava para a valorização da paz e da justiça social - daí a vida no campo aparecer como um grande ideal -, para a valorização nostálgica dos costumes simples do campo em confronto com as dificuldades e fracassos encontrados na vida da cidade.

Seguindo essa linha, Viriato Corrêa lança uma série de livros destinados ao público infantil desde 1908 (Era uma vez - livro de contos) e, dentre eles, 
um dos que mais seguem o estilo didático moralista de Coração é Cąuఇa. Lançado em 1938 e continuamente reeditado, gerado por idéias e ideais do Brasil dos anos 1930, Cazuza traduziu em literatura os impulsos que estavam na raiz do grande movimento histórico nacional, então em processo, movimento que pode ser sintetizado como sendo o deslocamento de populações do campo para a cidade a fim de impulsionar a modernização do país.

Cazuza é a história de um menino que dá título ao livro e que, depois de adulto, resolve escrever suas memórias de infância; liga-se aos dois primeiros (Coração e Saudade) pela ênfase dada ao respeito às instituições, sendo a educação o meio ideal para o progresso do homem, e pela preocupação de confrontar a vida rural interiorana com a vida urbana. Apresenta uma nítida evolução sobre os anteriores, pois, com experiências simples, Cazuza vai tendo oportunidade de revelar o jogo das relações humanas, o idealismo humanitário que deve nortear as ações de todos, as diferenças inerentes aos vários meios sociais. Cazuza foi dos que abriram as portas da literatura para os ventos da vida real, com linguagem mais ágil, mostrando também experiências necessárias ao indivíduo no seu processo de crescimento.

Mesmo assim, o didatismo moralizante ainda se faz presente, conforme o trecho abaixo:

Essa riqueza, de que você tem tanto orgulho, foi você que a juntou com sua inteligência, com seu suor e com seu esforço? Pensa você que o Custódio lhe é inferior porque é pobre? Pois é justamente a pobreza que lhe dá valor. Sendo paupérrimo, o Custódio come mal, dorme mal e o tempo que deve empregar no estudo, emprega-o em serviço caseiro, para ajudar os pais. A lição que ele traz sabida vale mais do que a lição sabida que você traz. Você tem tempo e conforto. Custódio não tem nada, senão a vontade de aprender, o brio de cumprir o seu dever de estudante. (CORRÊA, 1999: 85)

Vários autores tiveram influência nessa época, foram demasiadamente lidos pelas crianças e exerceram papel marcante na vida escolar do Brasil. Além dos citados, podemos enumerar autores como Olavo Bilac, Manuel Bonfim, Júlia Lopes de Almeida, Adelina Lopes Vieira, entre outros; como mantenedores do pensamento da classe dominante no que se refere à política ou às maneiras de se viver em sociedade, para a totalidade deles, a criança 
é vista como um indivíduo pronto para receber a educação como dádiva, como caráter divino, amando sua pátria como berço e fonte inesgotável de benevolências.

A educação e a leitura no Brasil, até o surgimento de Monteiro Lobato, eram o reflexo dos paradigmas vigentes, ou seja, o nacionalismo, o intelectualismo, o tradicionalismo cultural com modelos de cultura a serem imitados - desprezando-se totalmente as manifestações culturais surgidas aqui no país -; divulgavam-se o humanismo dramático e o moralismo religioso, com as exigências de retidão de caráter, de honestidade, de solidariedade e de pureza de corpo e de alma em conformidade com os preceitos cristãos. Todos esses elementos eram oriundos de ideologias impostas pelas classes dominantes, que buscavam na educação e nos primeiros esboços de literatura para crianças e jovens a concretização e perpetuação de seus anseios.

Com o surgimento de Monteiro Lobato, a criança passa a ter voz, ainda uma voz emitida por uma boneca de pano, Emília, mas cuja irreverência infantil sem barreiras começa a ser lida e vista por meio de ilustrações das personagens do Sítio do Picapau Amarelo. Nessa proposta inovadora, outras discussões culturais são inseridas nas figuras de personagens importantes na estrutura do sítio, tais como a Tia Nastácia, o Visconde, o Rabicó, entre outras.

Lobato apresenta características até então não exploradas no universo literário para crianças: apelo a teorias evolucionistas para explicar o destino da sociedade; a onipresença da realidade brasileira; olhar empresarial e patronal, que é fruto de um homem da sua condição naquela época; a preocupação com problemas sociais, além de soluções idealistas e liberais para tais problemas, todas tentativas de despertar no leitor uma flexibilidade diante do modo habitual de ver o mundo; relativismo de valores; questionamento do etnocentrismo; e visão do misticismo como resultado da miséria e da ignorância do povo.

Evidentemente, Lobato foi o precursor de uma nova literatura destinada às crianças no Brasil, uma literatura que passaria por inúmeras transformações e ainda por várias transferências, principalmente européias, por uma ditadura militar e por grandes mudanças na tecnologia e na sociedade, já que os sistemas literários estão vinculados a macrossistemas culturais.

Essas mudanças foram, de maneira histórica e dialógica, trazendo para a chamada literatura infantil uma diversidade de valores do mundo contempo- 
râneo, vários questionamentos do papel do homem diante de um universo que se transforma a cada dia e, além disso, trouxeram também as vozes de diferentes contextos sociais e culturais presentes na formação do povo brasileiro, sua diversidade e dificuldades de sobrevivência e, o mais importante, trouxeram as vozes e os sentimentos da criança para as páginas dos livros, para as ilustrações e para as diferentes linguagens que se fazem presentes na produção artística para crianças.

Autores como Pedro Bandeira, Carlos Queiroz Telles, Lúcia Pimentel Góes e Roseana Murray, entre outros, trazem essas vozes das crianças e o universo cotidiano com seus conflitos para serem lidos, vistos, sentidos e vivenciados na literatura infantil de hoje, conflitos esses levados às crianças com uma proposta de diálogo, não somente de imposição de valores, por meio de uma literatura que busca a arte, sua característica primeira e que procura cada vez mais trazer à tona as discussões sobre a identidade complexa do povo brasileiro, com todas as nuanças formadoras de nossa cultura plural.

Uma obra que coloca de maneira marcante a visão questionadora da criança de hoje, além de trazer a discussão sobre a diversidade étnica e cultural do povo brasileiro, é o livro Diversidades de Tatiana Belinky (1999), um bom exemplo da literatura feita para as crianças que procura enfocar uma moralidade menos rígida e aberta a questionamentos, o que se faz sentir na verbalidade e na visualidade, já que o livro traz uma quantidade maior de textos visuais.

O livro procura descrever diferenças que existem entre os seres humanos, seja na sua aparência, seja na forma que cada um, mediante a sua história de vida, tem de encarar a vida ou manifestar suas emoções.

Há, então, relações de diferença estabelecidas entre branco e negro, feio e bonito, jovem e idoso, entre outras.

As diferenças vão construindo o desenrolar da narrativa, e, no final do livro, encontramos:

Cada um na sua

E não fez mal

Di-ver-si-da-de

É que é legal! (BELINKY, 1999: 33). 
Nas duas últimas páginas, em que o texto visual é composto pela imagem de vários rostos exatamente iguais e sobrepostos, lemos:

\author{
Vamos, venhamos \\ Isto é um fato: \\ Tudo igualzinho \\ Ai, como é chato! (BELINKY, 1999: 34).
}

Nota-se, por meio desses poucos exemplos, que existe a discussão de um dos temas mais significativos hoje no Brasil: a diversidade étnica e cultural do seu povo.

Voltado para leitores iniciantes, já que o texto verbal se mostra bem reduzido e construído com sintaxe e vocabulário fáceis, o livro pode ser apreciado e discutido por todos os tipos de leitor, até o mais crítico, já que a temática e sua visualidade lúdicas fazem com que ampliemos a sua significação por meio da inserção de outras discussões mais profundas.

Além da obra de Belinky, é importante para esta discussão citar a obra $A$ cor de Ângela Leite de Souza (1996), em virtude de ela oferecer a possibilidade de resgate de uma brincadeira bastante divulgada nas décadas de 1960 e 1970 por meio das revistas de histórias em quadrinhos: a carta enigmática.

A carta enigmática é um tipo de texto no qual são inseridas ilustrações em meio ao texto verbal a fim de que se dificulte a sua leitura, transformando o ato de ler num jogo e, portanto, dando-lhe um caráter mais lúdico.

O livro $A$ cor é construído exatamente desse modo, isto é, em um breve texto verbal, o narrador insere figuras que remetem ao universo imaginário de expressões e ditos populares do Brasil, para que o seu leitor possa entender e apreender a mensagem contida na obra: a coisa mais importante é perceber que os sentimentos têm cor.

Por meio das imagens criadas para complementar o texto verbal, são feitas alusões a expressões populares do nosso país, como "passarinho verde" (significando a felicidade repentina de uma pessoa); "rosa", significando uma vida feliz e sem problemas; "azul”, indicando que está tudo correndo bem na vida de alguém. 
Além de serem inseridos no texto desenhos que remetem a alguns ditados populares, cada cor é representada com a página colorida, isto é, a rosa traz rosas em tom de rosa, os passarinhos são verdes e assim por diante.

As duas últimas páginas misturam no texto visual os recortes de todos os elementos que já apareceram no texto para indicar o que havíamos dito anteriormente: os sentimentos são coloridos.

A obra, entendida sob esse ponto de vista, não somente favorece a associação com frases corriqueiras de nossa cultura, mas traz importante contribuição para que se construa um leitor mais competente e plural, um leitor que consiga ler inúmeras linguagens além da verbal, que perceba a diversidade de linguagens que podem ser empregadas na construção de uma única mensagem ou obra de arte.

Os dois exemplos já conseguem mostrar que os valores sociais mudaram e a voz da criança já se faz ouvir; há o descrédito da autoridade que se coloca no poder por meio de uma moral dogmática; a linguagem se mostra mais próxima do falar infantil, e é nesse relativismo de valores que a criança terá de se situar como cidadã.

Podemos, desse modo, verificar momentos bem definidos da literatura voltada para as crianças no Brasil e entender esse percurso em busca de uma arte que busca discutir fatores importantes para a nossa identidade como povo, não simplesmente importar elementos de outras culturas.

Evidentemente, tudo o que dissemos por meio da utilização dos dois últimos exemplos diz respeito a paradigmas emergentes, a um momento em construção, mas o que se pretende é ressaltar a mudança dos objetivos e de mecanismos de construção de um tipo de texto cujo destinatário é a criança e que procura se firmar como literatura, sem que se descarte a sua presença demasiadamente importante no processo educativo, entendendo que o processo educativo também é construído hoje tentando levar em consideração a formação plural do povo brasileiro e não apenas reproduzindo padrões europeus.

Assim, temos a literatura infantil construída por meio de um diálogo constante com a sociedade, colocando em discussão aspectos ideológicos (políticos, religiosos, etc.), como visão de mundo de uma cultura em interface com as culturas de outros povos que partilham sua língua, como as nações africanas de língua oficial portuguesa, que antes não figuravam na tradição da 
literatura para crianças, já que os padrões a serem seguidos eram os ditados pelos modelos europeus de cultura.

Ao mesmo tempo em que essa nova literatura feita para crianças e para jovens traz à tona as discussões de valores sociais imprescindíveis para a identidade de nosso povo e para o diálogo com os outros povos de língua portuguesa, devolve para a sociedade novas maneiras artísticas de discutir e veicular esses valores, seja por meio de novas e múltiplas linguagens, seja por intermédio de novas formas de suporte para que essa arte seja veiculada.

\section{Referências Bibliográficas}

ANDRADE, Tales de. Saudade. São Paulo: Companhia Editora Nacional, 2002.

BANDEIRA, Pedro. Cavalgando o arco-iris. São Paulo: Moderna, 2002.

BELINKY, Tatiana. Diversidade. Ilustrações de Fernando Luiz. São Paulo: Quinteto Editorial, 1999.

CARVALHAL, Tania Franco (org.). Culturas, contextos e discursos. Porto Alegre: Ed. Universidade/UFRGS, 1999.

COELHO, Nelly Novaes. Literatura infantil: história, teoria, análise. São Paulo: Moderna, 2000.

. Panorama histórico da literatura infantill juvenil. São Paulo: Ática, 1991.

CORRÊA, Viriato. Cazuza. São Paulo: Companhia Editora Nacional, 1999.

DE AMICIS, Edmundo. Coração. São Paulo: Hemus, 1974.

GREGORIN FILHO, José Nicolau. A roupa infantil da literatura. Dissertação de Mestrado. Faculdade de Ciências e Letras da Unesp. Araraquara, 1995.

LOPES, Edward. A palavra e os dias: ensaios sobre a teoria e a prática da literatura. São Paulo: Editora da Universidade de Campinas, 1993.

MELLO E SOUZA, Antonio Candido. Literatura e sociedade. São Paulo: T. A. Queiroz, 2000 .

NITRINI, Sandra. Literatura Comparada: história, teoria e crítica. São Paulo: Editora da Universidade de São Paulo, 2000.

SOUZA. Ângela Leite de. A cor. Curitiba: Arco-íris, 1996.

TELLES, Carlos Queiroz. Abobrinha quando cresce. São Paulo: Moderna, 1993. 